\title{
Cambering of Four High Cold Mill with the View of Reducing Roller Ends Contact and Preventing Complex Waves
}

\author{
Zhenhua Bai ${ }^{1,2}$, Hongxin Si ${ }^{1}$, Xiaodong Shi ${ }^{1}$, Qingtian Zhou ${ }^{1}$ \\ ${ }^{1}$ School of Mechanical Engineering, State Key Laboratory of Metastable Materials Science and Technology, \\ YanShan University, Qinhuangdao, China \\ ${ }^{2}$ State Key Laboratory of Metastable Materials Science and Technology, YanShan University, \\ Qinhuangdao, China \\ E-mail:bai_zhenhua@yahoo.com.cn, \{sihongxin,xiaodong_shi\}@126.com \\ Received January 10, 2011; revised March 3, 2011; accepted March 11, 2011
}

\begin{abstract}
Based on lots of field experiments and theoretical research, fully thinking the equipment and production craft characters of four high cold mill, a new cambering scheme for four high cold mill is advanced in this paper. This scheme considered the need of production of multi-specification products, as well as the control of roller ends contact. The most homogeneous transverse distribution of front tension is the control target and the homogeneous pressure distribution between rollers is the constraint condition. In this technology, working roll curve adapt the combination of cosine curve and high order curve, backup roll adapt the combination of cosine curve, straight line and high order curve. The cosine subentry of working roll and the high order curve subentry are used to control edge wave, the high order curve subentry of working roll is used to control the roll contact, the cosine subentry of backup roll is used to reduce the center wave. That's the features of this technology. On-site testing shows that the new cambering and combination can not only manage the complex waves of normal four high cold mill effectively, but also will reduce the contact between roller ends and minish roll consumption. This technology has created economic benefits for enterprises.
\end{abstract}

Keywords: Complex Waves, Strip Shape, Roll Contour, Roll Contact, Roll Consumption

\section{Introduction}

In recent years, with the rapid development of manufacturing industry, customers put forward higher and higher requirements for the dimension accuracy of cold rolling strip and coated production. As the important qualitative index, strip shape will directly affect the plate yield, the quality of further processed product and the smooth proceeding of further processing, at the same time, the requirement for strip shape is the strictest in the product quality indexs (including property, guage, strip shape and surface quality). For the normal four high cold mill which don't have the function of shift movement and only has few methods of online strip shape control, the cambering technology is specially important. Formerly, the cambering of four high cold mill in production site only aimed to a single wave, for example, when there are many edge waves, the convex roll-shape of working roll and backup roll is often adopted; when there are many center waves, the disposition form of roll configuration curves is the concave roll-shape of working roll and plain roll-shape of backup roll. These above disposition forms of roll configuration curves often can't do anything about complex waves, even will lead to new wave defects. Specially, it is found that existing literature which are related with this paper, such as patent documentation, non-patent documents and other public technology, mainly focus on temper rolling and the mill which have axial movement device for the design proposal of roll configuration curves after "roll shape" and "curve" were retrieved as the keywords through literature retrieval institutions. Representative examples as follows: the patent, entitled "A method for roll configuration curve in the temper rolling process of thin and narrow strip" $[1,2]$, the application number is CN200610012600.5. A design proposal of back-up roll configuration curves and work- 
ing roll configuration curves is put forward in this patent for the purposes of ensuring the finished product's mechanical capacity and improving strip shape in the temper rolling process of thin and narrow strip; the patent, entitled "A method for roll configuration curve in hot dip galvanizing temper mill" $[3,4]$, the patent application number is CN200510029216.1. Hot dip galvanizing temper mill is taken as research object in this patent. A design proposal of back-up roll configuration curves and working roll configuration curves is put forward in this patent for the purposes of ensuring the stability of zinc coating and the uniformity of spangles and improving strip shape in the temper rolling process. The paper, called "Research of the Roll Crown Optimization on Skin Pass Mill in Baosteel 2050 Hot Rolling Plant" [5,6], published in "Steel" journal in No. 9, 2002, considered the problem of shape in hot rolling temper mill only, and a design proposal of back-up roll configuration curves and working roll configuration curves is put forward in this paper. All the above cambering technology takes temper rolling with small elongation as research object. The problems solved in the above cambering technology are different with this technology introduced in this paper. Related technology can't be copied to tandem cold rolling with heavy reduction rate which is aimed at managing complex seas. The patent, entitled "A back-up roll configuration curve which cooperate with the working roll configuration curve of continuous variable crown mill", the application number is CN200510024680.1 [7]; the patent, entitled "A back-up roll configuration curve which is fit for the working roll with axial movement device to change roll gap crown", the application number is CN200410008195.0 [8]; the patent, entitled "A variable gap's roll shape which is fit for the working roll with axial movement device to change roll gap crown", the application number is CN95117449.5 [9]; the patent, entitled "A working roll configuration curve which takes account of both shape control and Schedule Free Rolling", the application number is CN200510046113.6 [10]; all take the mill which have axial movement device as research object, and the target of these patent is to reduce roll consumption and to improve shape. The above cambering technology all take the mill which have axial movement device as research object, suitable for the CVC mill's cambering, not suitable for 4- high cold tandem mill. So, the emphasis of field breakthrough is how to effectively control the complex wave defects of four high cold mill from the point of roll configuration curves. For this reason, after lots of field experiments and theory research, a new technology of cambering which is fit for normal four high cold mill was put forward, the optimized roll configuration curves can accommodate different strip shape, not only can manage the complex waves but also can manage the single wave and reduce the contact of roller ends. This technology has important effects on ensuring the stability of strip shape and has created economic benefits for domestic steel makers.

\section{Scheme of Cambering}

\subsection{Basic Design Idea}

For the need of on-site shape control, the management of complex waves and single waves are taken into account, the most homogeneous transverse distribution of front tension is the control target and the homogeneous pressure distribution between rollers is the constraint condition, and for reducing the contact of roller ends at the same time, a new cambering technology of four high cold mill was put forward, the basic design idea is that working roll curve adopt the combination of cosine curve and high order curve, backup roll adopt the combination of cosine curve, straight line and high order curve. Using the cosine subentry of working roll and the high order curve subentry of backup roll to control the edge wave, the high order curve subentry of working roll control the contact, and the cosine subentry of backup roll reduce the center wave. It should be specially explained that all the design thoughts in this paper is demonstrated for the first time and is the innovation of this paper.

\subsection{Specific Plan of Cambering}

Based on lots of field experiments and theory research, as shown in Figure 1, the roll configuration curves of working roll adopt the curve form which is expressed with Equation (1).

$$
D_{w}(x)=D_{w}-a \times\left(1-\cos \left(b_{w} \cdot \frac{2 x}{L_{w}}\right)\right)-c \times\left(\frac{2 x}{L_{w}}\right)^{k_{w}}
$$

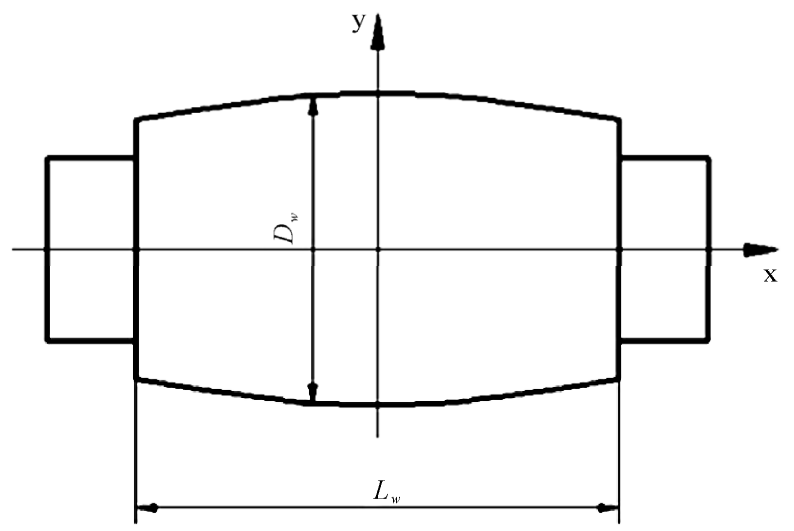

Figure 1. Schematic diagram of the work roll contour curve. 
where $D_{w}$ is the original diameter of working roll, $L_{w}$ is the face length of working roll, $a$ is the crown value of working roll, $b_{w}$ is the cosine phase coefficient of working roll, $k_{w}$ is the high order curve subentry index of working roll.

Obviously, for the description of the roll configuration curves of working roll which is described in Figure 1 and Equation (1), $a, b_{w}, c, k_{w}$ need to be given.

For the backup roll, based on field experiments and theory research, the roll configuration curves of working roll adopt the curve form which is expressed with Equation (2) (as shown in Figure 2):

$$
D_{b}(x)= \begin{cases}D_{b}-d \times\left(1-\cos \left(b_{b} \cdot \frac{\pi x}{e}\right)\right) & |x| \leq e \\ D_{b} & e<|x| \leq \frac{L_{b}}{2}-f \\ D_{b}-2 \times g \times\left(\frac{|x|-\left(L_{b} / 2-f\right)}{f}\right)^{k_{b}} & |x|>\frac{L_{b}}{2}-f\end{cases}
$$

where $D_{b}$ is the original diameter of backup roll, $L_{b}$ is the face length of backup roll, $d$ is the crown value of backup roll's middle, $b_{b}$ is the cosine phase coefficient of backup roll, $e$ is the half length of concave curve in the backup roll's middle, $f$ is the length of backup roll's high order curve, $g$ is the high order curve subentry coefficient of backup roll, $k_{b}$ is the high order curve subentry index of backup roll.

For the description of the roll configuration curves of backup roll which is described in Figure 2 and Equation (2), $d, e, f, g, k_{b}, b_{b}$ need to be given.

It should be noted that in the disposition form of the roll configuration curves of working roll and backup roll, the cosine subentry of working roll, namely, $a \times\left(1-\cos \left(b_{w} \cdot \frac{2 x}{L_{w}}\right)\right)$, the high order curve subentry of

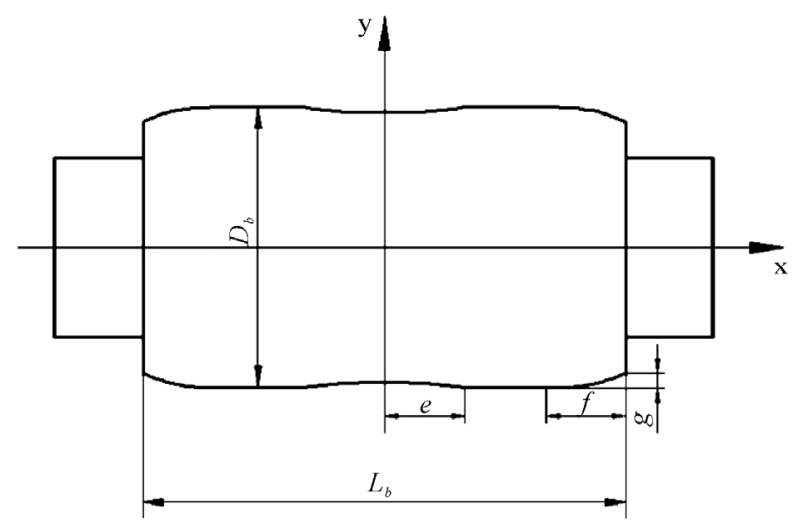

Figure 2. Schematic diagram of back-up roll contour curve. backup roll, namely $2 \times g \times\left(\frac{|x|-\left(L_{b} / 2-f\right)}{f}\right)^{k_{b}}$, are used to manage edge wave; the subentry of working roll, namely, $c \times\left(\frac{2 x}{L_{w}}\right)^{k_{w}}$, is used to manage contact; the subentry of backup roll, namely, $d \times\left(1-\cos \left(b_{b} \cdot \frac{\pi x}{e}\right)\right)$, is used to manage center wave.

Then, in the synthesis may know, according to the practical situation of the unit, through the reasonable optimization grouping for $a, b_{w}, c, k_{w}, d, e, f$, $g, k_{b}, b_{b}$ can effectively cure various forms of wave. Particularly, when the four high cold mill mainly produce the thick plate, contact don't exist, at this time, $c$ is $0, c \times\left(\frac{2 x}{L_{w}}\right)^{k_{w}}$ disappear. In the grinding of roll configuration, a point per five millimeters, according to Equations (1)-(2) to calculate the correspond diameter of roll, and then input the grinder for grinding.

\subsection{Objective Function of Cambering}

When produce all kinds of products of Product mix, this technology should satisfy the following three requirements: 1) curing complex waves and ensuring good strip shape; 2) reducing contact; 3 ) the homogeneous pressure distribution between rollers, peak value don't exceed the limitation, reducing roll wear. This is the purpose of this technology. It should be noted that in practical design the field often choose $\mathrm{m}$ specifications for optimization, and according to the portion of total amount to weight, the more often produced the product is, the weighting coefficient is more larger. Based on lots of field experiments and theoretical research, the following objective control function are given.

$$
\left\{\begin{array}{l}
G(x)=\sum_{j=1}^{m} \sqrt{\frac{\alpha_{j} \sum_{i=1}^{n}\left(\sigma_{1 i j}-\beta_{i j}\right)^{2}}{T_{i j}}} \\
q_{i j}<\sigma_{\max } \\
\frac{\max \left(q_{i j}\right)-\min \left(q_{i j}\right)}{\frac{1}{n} \sum_{i=1}^{n} q_{i j}} \leq \beta_{\max } \\
\delta_{i} \leq \delta_{\max }
\end{array}\right.
$$

where $m$ is the amount of typical product specifications, $\sigma_{\max }$ is the maximum permissible stress of roll, $\beta_{\max }$ is the maximum nonuniformity coefficient of pressure between rolls, $\delta_{\max }$ is the maximum contact 
amount of roll end, $\sigma_{1 i j}$ is the shape distribution value of the $\mathrm{j}$-th typical product specification, $\delta_{j}$ is the contact length of the $j$-th typical product specification, $q_{i j}$ is the transverse distribution value of the pressure between rolls of the $j$-th typical product specification, $T_{i j}$ is the average front tension of the $j$-th typical product specification, $\beta_{i j}$ is the setting shape value in the $i$-th segment of the $j$-th typical product specification, $\alpha_{j}$ is the weighting coefficient, $n$ is the amount of lateral elements.

$$
\text { In Equation (3), } G(x)=\sum_{j=1}^{m} \sqrt{\frac{\alpha_{j} \sum_{i=1}^{n}\left(\sigma_{1 i j}-\beta_{i j}\right)^{2}}{T_{i j}}} \text { is used }
$$
to manage the complex waves and single waves, $\delta_{i} \leq \delta_{\max }$ is used to control contact, $\frac{\max \left(q_{i j}\right)-\min \left(q_{i j}\right)}{\frac{1}{n} \sum_{i=1}^{n} q_{i j}} \leq \beta_{\max }$ and $q_{i j}<\sigma_{\max }$ are used to ensure the uniformity of the lateral distribution of pressure between rolls and prevent the peak value exceeding the limitation.

Due to all kinds of product specifications have been considered in the objective function, so new roll configuration has a good adaptability for the width, thickness and strength of strip. It should be specially explained that all the design thoughts in this paper is demonstrated for the first time and is the innovation of this paper.

\section{On-Site Application of New Cambering Technology}

A domestic five-stand 1220 cold-rolling mills in order to manage the complex waves existed in mill exit and reduce the contact between roll ends, using the technology described in this article to have optimized the roll con- figuration curves of working roll and backup roll for the fifth stand. Field practical application shows that this technology has a good effect and created huge economic benefits over three million per year. The basic information as follows:

\subsection{The Roll Configuration Curve of Working Roll}

According to practical Product mix of five-stand 1220 cold-rolling mills, for the roll configuration curve of working roll, there are two roll configuration curves including thickness over $3 \mathrm{~mm}$ and less $3 \mathrm{~mm}$. For the former contact need to be considered, the latter don't. The basic equation is as Equation (4).

\subsection{The Roll Configuration Curve of Backup Roll}

The equation of backup roll's configuration curve (see Equation (5)).

\subsection{Tracking}

According to the on-site statics, before adopting the new technology, the wave height information was 40 percent of products less than $4 \mathrm{~mm}, 40$ percent of products greater than $4 \mathrm{~mm}$ and less than $10 \mathrm{~mm}, 20$ percent of products greater than $10 \mathrm{~mm}$, the average wave height was $6.23 \mathrm{~mm}$, the incidence of complex wave almost reached to 100 percent, the sealing rate of shape is 2.37 per thousand. After the new technology was adopted, the wave height information was 95 percent of products less than $4 \mathrm{~mm}$, the average wave height was $3.35 \mathrm{~mm}$, the incidence of complex wave was controlled in 20 percent, the sealing rate of shape reduced to 0.52 per thousand. At

$$
\begin{aligned}
& D_{w}(x)= \begin{cases}D_{w}-2.12 \times 10^{-5}\left(1-\cos \left(\frac{65 \pi}{180} \cdot \frac{2 x}{l_{b}}\right)\right)-6.1 \times 10^{-5} \times\left(\frac{2|x|}{l_{b}}\right)^{6} & \text { for thin strip } \\
D_{w}-2.835 \times 10^{-5} \times\left(1-\cos \left(\frac{140 \pi}{180} \cdot \frac{2 x}{l_{b}}\right)\right) & \text { for thick strip }\end{cases} \\
& D_{b}(x)=\left\{\begin{array}{lr}
D_{b}-0.015 \times 2 \times\left(1-\cos \left(\frac{2 \pi x}{400}\right)\right) & |x| \leq 200 \\
D_{b} & 200<|x| \leq 320 \\
D_{b}-2 \times 0.12 \times\left(\frac{|x|-\left(\frac{L}{2}-320\right)}{320}\right) & |x|>320
\end{array}\right.
\end{aligned}
$$


the same time, After the new roll configuration curve was adopted, the curve of rolling wear become more homogeneous, rolling wear was reduced effectively.

\section{Conclusions}

1) Considering the production of various product specifications, the most homogeneous transverse distribution of front tension was defined as the target, the control of contact is also considered, the homogeneous pressure distribution between rollers was defined as the constraint condition, a new cambering technology of four high cold mill was put forward. In this technology, working roll curve adopt the combination of cosine curve and high order curve, backup roll adopt the combination of cosine curve, straight line and high order curve.

2) In this new technology, the cosine subentry of working roll and the high order curve subentry of backup roll were used to control the edge wave, the high order curve subentry of working roll was used to control the contact, and the cosine subentry of backup roll was used to reduce the center wave.

3) Through the on-site use for this new cambering scheme, the average wave height reduced from $6.23 \mathrm{~mm}$ to $3.35 \mathrm{~mm}$, the incidence of complex wave reduced from 2.37 per thousand to 0.52 per thousand, the curve of rolling wear become more homogeneous.

\section{Acknowledgements}

Contract/grant sponsor and Grant Number:

1) Hundred Excellent Researchers Award Program of Department of Education of Hebei Province. Grant Number: CPRC018.

2) Natural Science Foundation of Hebei Province (Surface Project). Grant Number: E2011203019.

3) Natural Science Foundation of Hebei Province (Base Special Fund). Grant Number: 08B015.

4) Training and Selection of Subject Top-notch Personnel in University of Hebei Province. Grant Number: 50374058 .

\section{References}

[1] Z. H. Bai, X. Z. Feng and Y. F. Jiang, "Research on Reform Program of Roll Shape in Skin Rolling Process of Super Thin Strip," China Mechanical Engineering, Vol. 18, No. 23, 2007, pp. 2887-2890.

[2] Z. H. Bai, "A Method for Roll Configuration Curve in the Temper Rolling Process of Thin and Narrow Strip," Patent for an Invention, China, Patent Number: CN2006100 12600.5

[3] T. Q. Gu, Z. H. Bai and Y. S. Zhao, "A Method for Roll Configuration Curve in Hot Dip Galvanizing Temper Mill," Patent for an Invention, China, Patent Number: CN200510029216.1.

[4] Z. H. Bai, T. Q. Gu, A. M. Wu and J. C. Lian, Research on Technology about Roll Shape of 1800 3\# CGL Hot Galvanizing Temper Mill in Baosteel. China Mechanical Engineering, Vol. 17, No. 1, 2006, pp. 33-35.

[5] Z. H. Bai, J. C. Lian, F. Liu and J. Q. Wang, "Research of the Roll Crown Optimization on Skin Pass Mill in Baosteel 2050 Hot Rolling Plant," Steel, Vol. 37, No. 9, 2002, pp. 35-38.

[6] Z. H. Bai, "Research of Theory and Engineering Use about Roll Crown of 1450 Hot Rolling Temper Mill," Metallurgical Equipment, Vol. 23, No. 2, 2006, pp. 4-6.

[7] C. Q. Huang and J. C. Lian, "A Back-Up Roll Configuration Curve Which Cooperate with the Working Roll Configuration Curve of Continuous Variable Crown Mill," Patent for an Invention, China, Patent Number: CN 2005 10024680.1

[8] J. C. Lian and X. D. Qi, “A Back-Up Roll Configuration Curve Which is Fit for the Working Roll with Axial Movement Device to Change Roll Gap Crown," Patent for an Invention, China, Patent Number: CN200410008 195.0

[9] J. C. Lian, “A Variable Gap's Roll Shape Which is Fit for the Working Roll with Axial Movement Device to Change Roll Gap Crown," Patent for an Invention, China, Patent Number: CN95117449.5

[10] H. D. Huang, X. L. Chen and A. R. He, "A Working Roll Configuration Curve Which Takes Account of Both Shape Control and Schedule Free Rolling," Patent for an Invention, China, Patent Number: CN200510046113.6. 